\section{Perfis epidemiológicos de saúde bucal no Brasil e os modelos de vigilância}

\author{
Oral health epidemiology and \\ surveillance models in Brazil
}

\author{
1 Universidade Federal do \\ Rio Grande do Norte, Natal, \\ Brasil. \\ 2 Pontifícia Universidade \\ Católica de Minas Gerais, \\ Belo Horizonte, Brasil. \\ 3 Universidade Federal \\ de Santa Catarina, \\ Florianópolis, Brasil. \\ Correspondência \\ A. G. Roncalli \\ Universidade Federal do Rio \\ Grande do Norte. \\ Av. Salgado Filho 1787, Natal, \\ RN 59056-000, Brasil. \\ roncalli@terra.com.br
}

\begin{abstract}
National surveys are important tools for public health surveillance and thus key elements in monitoring health conditions and system performance. In the field of oral health, such surveys began with the oral health survey in 1986 and later in 1996 and with the SBBrasil Project in 2003. The 2010 edition of SBBrasil is the principal oral health surveillance strategy for the production of primary data. In order to contribute to this discussion, this article proposes: (a) to present and discuss the Brazilian experience with nationwide oral health surveys and (b) to discuss the use of data in health surveillance models. One can conclude that oral health surveys in Brazil have great possibilities as a tool for health services and academia. Such surveys have shown evident potential for verifying trends in the oral health profile, as well as for producing valid indicators for use in health services.
\end{abstract}

Dental Health Surveys; Oral Health; Epidemiologic Surveillance
Angelo Giuseppe Roncalli 1

Maria Ilma de Souza Côrtes 2

Karen Glazer Peres 3

\section{Introdução}

Os estudos transversais, também conhecidos como seccionais, de prevalência, inquéritos ou levantamentos epidemiológicos são importantes ferramentas no campo da vigilância em saúde. Fazem parte de um conjunto mais amplo das estatísticas de saúde, elementos fundamentais nos processos de monitoramento das condições de saúde e do desempenho do sistema de saúde 1 .

Além disso, conforme ressalta Barros 2, os inquéritos têm papel importante no monitoramento da equidade em saúde, tendo em conta a realidade da concentração de renda no país. Para a autora, isso tem implicações nas definições e escolhas de variáveis e indicadores.

Para Cesar \& Tanaka 3, entendendo a avaliação em saúde como uma composição de estrutura, processo e resultado, determinadas dimensões do processo e de parte do resultado só são plenamente abordadas valendo-se de estudos com base populacional. Isso ocorre pelo fato das informações que são obtidas a partir da demanda serem, na maior parte dos casos, “altamente seletivas, ocultando um dos aspectos mais importantes da avaliação de serviços de saúde nos países em desenvolvimento, e mesmo naqueles desenvolvidos: a iniquidade no acesso aos serviços de saúde" 3 (p. 62). Os autores ainda destacam a importância dos inquéritos domiciliares no aprimoramento da avaliação de resultado, uma vez que permitem a construção de "linhas de base", 
as quais servirão como parâmetros futuros de comparação.

E, por fim, é fundamental que os inquéritos nacionais sejam periódicos e regulares para que se possa conhecer a realidade epidemiológica da população baseando-se em cortes transversais periódicos e sequenciados, na opinião de Waldman et al. 4. Para os autores, diversos aspectos colocam os inquéritos como elementos fundamentais na estruturação das políticas de saúde: (a) permite correlacionar os resultados com as condições de vida das populações, conhecendo a distribuição dos fatores de risco e a percepção das pessoas a respeito do seu estado de saúde; (b) dá voz aos usuários dos serviços de saúde, contribuindo com o controle social; e (c) permitem avaliar as políticas públicas implementadas, comparando padrões de saúde entre áreas geográficas e realizando estudos de custo-efetividade.

Numa perspectiva histórica, os inquéritos de saúde de base populacional surgem inicialmente nos países desenvolvidos a partir da década de 1960, expandindo mais tardiamente também para os países do bloco subdesenvolvido. Em muitas situações, dada a precariedade dos sistemas de informação, os inquéritos se constituíam na única fonte de informação de saúde confiável nesses países 2. Os Estados Unidos realizavam seus primeiros levantamentos já no fim dos anos 1950, por intermédio do National Center for Health Statistics (NCHS), e tais inquéritos foram os precursores dos atuais National Health and Nutritional Examination Surveys (NHANES) que coletam, inclusive, informações de saúde bucal.

Ainda segundo Barros 2, devem ser destacadas as iniciativas do Canadá e de países da Europa, entre eles o Reino Unido, que apresentam bases de dados desde os anos 1940, e a recente Pesquisa Mundial de Saúde, conduzida pela Organização Mundial da Saúde (OMS) em 71 países, inclusive no Brasil.

A experiência brasileira recente demonstra que, a despeito de estar disponível uma gama diversa de dados oriundos dos sistemas de informação, persiste a necessidade de coletá-los sobre condições de saúde e uso de serviços, os quais só podem ser gerados por inquéritos populacionais periódicos. No âmbito do Ministério da Saúde, a Secretaria de Vigilância em Saúde (SVS/MS) tem produzido informações importantes para o planejamento e avaliação das ações baseando-se em inquéritos como o PeNSE (Pesquisa Nacional de Saúde do Escolar), o Projeto de Vigilância de Violência e Acidentes (VIVA) e a pesquisa sobre fatores de risco com base em inquérito telefônico (VIGITEL). Além disso, do ponto de vista interinstitucional, deve ser dado o devido destaque aos suplementos de saúde das PNADs (Pesquisa Nacional por Amostra de Domicílios) realizadas pelo Instituto Brasileiro de Geografia e Estatística (IBGE).

No campo da saúde bucal, segundo Narvai 5 , as primeiras experiências de estudos epidemiológicos sobre este assunto podem ser encontradas no Brasil desde o início dos anos 1950, dentro dos então chamados "programas incrementais". Tais estudos, a despeito de sua importância para a consolidação da epidemiologia em saúde bucal no Brasil, tinham uma abrangência muito restrita às áreas cobertas por esses programas, particularmente aquelas onde atuavam os Serviços Especiais de Saúde Pública (SESP). Desse modo, na prática, os inquéritos nacionais tornam-se realidade a partir da segunda metade dos anos 1980, com a realização do primeiro levantamento epidemiológico em saúde bucal de 1986 e, em seguida, 10 anos depois, a segunda experiência, com o levantamento de 1996 6,7. Embora esses estudos tenham tido grande importância no seu tempo, não se estabeleceram enquanto um componente da política de saúde bucal vigente, se conformando em iniciativas isoladas 8 .

A experiência seguinte é a do Projeto SBBrasil, que surgiu como uma ideia de construir um levantamento epidemiológico em saúde bucal de base nacional, inspirado na metodologia sugerida pela OMS no final dos anos 1990 9. A proposta original era realizá-lo no ano 2000 pelo fato de ser um ano-índice, além de compor o limite para o estabelecimento das metas recomendadas no programa Saúde Para Todos no Ano 2000 da própria OMS. Por questões operacionais, o levantamento só foi realizado entre 2002 e 2003 e teve seus dados publicados em 2004 e, por esta razão, o nome original do projeto (Projeto SB2000) passou a ser Projeto SBBrasil 2003.

Dentro das estratégias para a construção do eixo da vigilância em saúde da Política Nacional de Saúde Bucal foi sugerida a edição 2010 do SBrasil, a qual aperfeiçoou e modernizou a proposta metodológica do SBBrasil 2003 10. O Projeto SBBrasil, portanto, se coloca enquanto principal estratégia de vigilância em saúde bucal no eixo da produção de dados primários sobre o tema, contribuindo para a construção de uma Política Nacional de Saúde Bucal pautada em modelos assistenciais de base epidemiológica.

No sentido de contribuir com a discussão acerca da importância dos inquéritos epidemiológicos na estruturação de modelos assistenciais com base na vigilância em saúde, este artigo propõe os seguintes objetivos: (a) apresentar e discutir a experiência brasileira em inquéritos nacionais de saúde bucal, destacando a estratégia recente do Projeto SBBrasil em suas versões 2003 
e 2010, e (b) discutir a possibilidade de utilização dos dados de inquéritos nacionais em modelos de vigilância em saúde.

\section{Método}

Para o primeiro objetivo, foi realizada uma revisão da literatura e a consulta aos principais documentos relativos às experiências recentes de inquéritos epidemiológicos nacionais conduzidos pelo Ministério da Saúde.

Para o segundo, foi realizada uma análise dos principais indicadores que podem ser produzidos baseando-se em dados de inquéritos de saúde bucal. O banco de dados do SBBrasil 2003 foi utilizado como uma primeira aproximação para a produção de uma matriz de indicadores de cárie dentária, e os resultados foram analisados no sentido de destacar sua capacidade de gerar informações relevantes para um modelo de vigilância.

\section{Resultados e discussão}

Inquéritos nacionais de saúde bucal: a experiência brasileira

Os inquéritos nacionais de saúde bucal entram na história sanitária brasileira a partir de 1986, com a realização do primeiro levantamento epidemiológico de saúde bucal de abrangência nacional. Na verdade, a pesquisa foi feita em 16 capitais, as quais representaram as 5 regiões naturais (Norte, Nordeste, Sudeste, Sul e Centro-oeste), mas pode ser considerada a primeira estimativa mais confiável da realidade epidemiológica brasileira em saúde bucal. Em seguida, 10 anos depois, em 1996, realizou-se o segundo levantamento e, em 2003 e 2010, as duas edições do que ficou conhecido como Projeto SBBrasil.

Uma extensa revisão analítica dessas experiências até 2003 foi realizada por Roncalli em 2006. Para o autor, "as três principais iniciativas para a construção de diagnósticos de saúde bucal em nível nacional não se constituem apenas em um conjunto de dados gerados ao longo de 17 anos. A despeito de apresentarem características muito distintas, expressam o amadurecimento técnico-científico e também político da Epidemiologia e da Saúde Bucal Coletiva e tiveram sua importância em seu devido tempo. Foram fundamentais, portanto, para pavimentar o caminho de

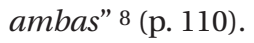

A Tabela 1 foi atualizada, sob a permissão do autor, com as informações referentes ao SBrasil 2010.
Uma das principais conclusões que se pode tirar a respeito do quadro, é que o Projeto SBBrasil se firma como a principal estratégia de produção de dados primários do componente de vigilância em saúde da Política Nacional de Saúde Bucal. Pela primeira vez uma pesquisa de abrangência nacional surge a partir da construção de uma política e não somente como uma oportunidade, como pareceram ser as experiências anteriores.

Do ponto de vista metodológico, aperfeiçoamentos importantes foram acrescentados na edição de 2010, particularmente com relação à técnica de pesquisa em domicílios. Alguns índices foram acrescentados, como por exemplo, a avaliação de traumatismo dentário, e outros foram modificados como o CPI (Índice Periodontal Comunitário) e a avaliação da necessidade de prótese. Com relação ao plano amostral, em 2010 as capitais foram consideradas como domínios do estudo. Uma maior racionalidade foi dada à pesquisa nos municípios do interior, compondo uma amostra de 30 municípios em cada região (totalizando 150), e o levantamento foi feito somente em domicílios da zona urbana.

No que diz respeito à análise de dados, é importante destacar que este foi um dos aspectos em que o SBBrasil 2003 mais sofreu críticas. Segundo Queiroz et al. 11, mesmo considerando uma amostra de mais de 108 mil indivíduos suas estimativas não são válidas para a população pelo fato de, entre outros aspectos, não terem sido considerados os pesos amostrais na produção destas estimativas. Além de não considerarem válidos os resultados para o país, os autores ainda destacam que todos os estudos de associação, realizados posteriormente com o banco de dados do SBrasil 2003, também apresentam problemas de validade.

No ano seguinte, Narvai et al. 12 apresentaram uma contra-argumentação à publicação de Queiroz et al. 11, o que resultou em artigo de debate no número 4 de 2010 de Cadernos de Saúde Pública. A centralidade do argumento de Narvai et al. é que o conceito de validade científica, no caso de estudos epidemiológicos, não deve ser restrito às questões estatísticas e matemáticas. A eventual diferença nas estimativas ponderadas $\mathrm{e}$ não ponderadas podem ser relevantes em termos matemáticos, mas não em termos epidemiológicos. Os autores demonstram que a leitura e a discussão dos dados produzidos não se alteram pela introdução das estatísticas ponderadas.

De toda maneira, há um reconhecimento de que, em estudos epidemiológicos com amostra complexa, em que as probabilidades dos elementos amostrais são diferentes, torna-se necessário aplicar as devidas ponderações. Para 
Principais características dos quatro levantamentos epidemiológicos realizados no Brasil.

\begin{tabular}{|c|c|c|c|c|}
\hline $\begin{array}{l}\text { Categorias de } \\
\text { análise }\end{array}$ & 1986 & 1996 & 2003 & 2010 \\
\hline $\begin{array}{l}\text { Cenário político- } \\
\text { sanitário }\end{array}$ & $\begin{array}{l}\text { Redemocratização do } \\
\text { país (Nova República); } \\
\text { Crescimento e } \\
\text { amadurecimento do } \\
\text { Movimento Sanitário; VIII } \\
\text { Conferência Nacional de } \\
\text { Saúde; Divisão Nacional de } \\
\text { Saúde Bucal (DNSB) }\end{array}$ & $\begin{array}{l}\text { Primeiro mandato de } \\
\text { Fernando Henrique Cardoso; } \\
\text { Democracia representativa } \\
\text { aparentemente consolidada; } \\
\text { Avanço na implantação de } \\
\text { uma vertente econômica } \\
\text { neoliberal; Saúde Bucal } \\
\text { como Área Técnica no } \\
\text { Ministério da Saúde }\end{array}$ & $\begin{array}{l}\text { Início do projeto no } \\
\text { segundo mandato de } \\
\text { Fernando Henrique Cardoso } \\
\text { e conclusão no início do } \\
\text { governo Luiz Inácio Lula da } \\
\text { Silva; Pouca ou nenhuma } \\
\text { mudança na política } \\
\text { macroeconômica; Política } \\
\text { de Saúde Bucal priorizada } \\
\text { no conjunto de políticas } \\
\text { públicas; Rearticulação da } \\
\text { Coordenação Nacional de } \\
\text { Saúde Bucal; III Conferência } \\
\text { Nacional de Saúde Bucal }\end{array}$ & $\begin{array}{c}\text { Projeto desenvolvido ao } \\
\text { longo do segundo mandato } \\
\text { de Luiz Inácio Lula da Silva; } \\
\text { Manutenção da política } \\
\text { macroeconômica; Política de } \\
\text { Saúde Bucal ainda priorizada } \\
\text { no conjunto de políticas } \\
\text { públicas }\end{array}$ \\
\hline $\begin{array}{l}\text { Cenário } \\
\text { epidemiológico }\end{array}$ & $\begin{array}{l}\text { Alta prevalência e severidade } \\
\text { de cárie dentária em } \\
\text { escolares; Alto índice de } \\
\text { edentulismo em adultos } \\
\text { e idosos; Desigualdades } \\
\text { regionais no perfil } \\
\text { epidemiológico }\end{array}$ & $\begin{array}{l}\text { Tendência de queda } \\
\text { da cárie da população } \\
\text { escolar; Persistência de } \\
\text { desigualdades regionais }\end{array}$ & $\begin{array}{l}\text { Confirmação da tendência } \\
\text { de declínio da cárie dentária } \\
\text { na população escolar (12 } \\
\text { anos); Persistência de } \\
\text { grandes desigualdades } \\
\text { regionais; Concentração } \\
\text { do declínio e de melhores } \\
\text { condições de saúde bucal } \\
\text { em área urbana de capitais } \\
\text { do Sul e Sudeste e em alunos } \\
\text { de escola privada; Quadro } \\
\text { de edentulismo ainda } \\
\text { alarmante; Surgimento de } \\
\text { outras necessidades como as } \\
\text { oclusopatias }\end{array}$ & $\begin{array}{l}\text { Confirmação da tendência } \\
\text { de declínio da cárie } \\
\text { dentária na população de } \\
12 \text { anos; Queda de } 25 \% \\
\text { em relação a 2003, maior } \\
\text { que o declínio entre } 1996 \\
\text { e 2003; Persistência das } \\
\text { desigualdades regionais; } \\
\text { Edentulismo ainda alto mas } \\
\text { com resultados positivos já } \\
\text { perceptíveis em população } \\
\text { adulta }\end{array}$ \\
\hline $\begin{array}{l}\text { Características } \\
\text { metodológicas }\end{array}$ & $\begin{array}{l}\text { Delineamento amostral } \\
\text { probabilístico com } \\
\text { representatividade em nível } \\
\text { macrorregional; Avaliação } \\
\text { de cárie dentária, doença } \\
\text { periodontal e edentulismo; } \\
\text { Zona urbana de } 16 \text { capitais; } \\
\text { Grupos etários de escolares } \\
\text { a idosos }\end{array}$ & $\begin{array}{c}\text { Modelo amostral não } \\
\text { probabilístico; Avaliação } \\
\text { somente de cárie dentária } \\
\text { em escolares de } 6 \text { a } 12 \text { anos; } \\
\text { Zona urbana de } 27 \text { capitais e } \\
\text { Distrito Federal }\end{array}$ & $\begin{array}{l}\text { Delineamento amostral } \\
\text { probabilístico com } \\
\text { representatividade em nível } \\
\text { macrorregional; Avaliação } \\
\text { de cárie dentária, doença } \\
\text { periodontal, edentulismo, } \\
\text { oclusopatias e fluorose. } \\
\text { Verificação de condições } \\
\text { socioeconômicas e acesso } \\
\text { a serviços; Zona urbana } \\
\text { e rural de } 250 \text { municípios } \\
\text { de diferentes portes } \\
\text { populacionais (de menos } \\
\text { de } 5 \text { mil a mais de } 100 \text { mil } \\
\text { habitantes); } 6 \text { grupos etários, } \\
\text { de bebês a idosos }\end{array}$ & $\begin{array}{l}\text { Manteve a estratégia } \\
\text { geral do modelo de 2003, } \\
\text { ou seja, delineamento } \\
\text { amostral probabilístico } \\
\text { com representatividade em } \\
\text { nível macrorregional e para } \\
\text { capitais; Pesquisa somente } \\
\text { em domicílios e não mais } \\
\text { em escolas para } 5 \text { e } 12 \\
\text { anos; Zona urbana de } 177 \\
\text { municípios (30 do interior } \\
\text { em cada região mais as } 27 \\
\text { capitais); } 5 \text { grupos etários } \\
\text { (5, 12, } 15-19,35-44 \text { e } 65-74 \\
\text { anos); Melhorias nas técnicas } \\
\text { de pesquisa de campo e nas } \\
\text { estratégias de análise }\end{array}$ \\
\hline
\end{tabular}

(continua) 
Tabela 1 (continuação)

\begin{tabular}{|c|c|c|c|c|}
\hline $\begin{array}{l}\text { Categorias de } \\
\text { análise }\end{array}$ & 1986 & 1996 & 2003 & 2010 \\
\hline $\begin{array}{l}\text { Articulação com a } \\
\text { política de saúde }\end{array}$ & $\begin{array}{l}\text { Vinculado ao Programa de } \\
\text { Prevenção de Cárie Dentária } \\
\text { (PRECAD); Sem continuidade }\end{array}$ & $\begin{array}{l}\text { Nenhuma política de } \\
\text { saúde bucal definida; Sem } \\
\text { continuidade }\end{array}$ & $\begin{array}{c}\text { Articulado à Política Nacional } \\
\text { de Saúde Bucal (Brasil } \\
\text { Sorridente); Continuidade } \\
\text { ainda indefinida }\end{array}$ & $\begin{array}{l}\text { Projeto inserido na Política } \\
\text { Nacional de Saúde Bucal } \\
\text { (PNSB) como componente } \\
\text { relativo aos dados primários } \\
\text { do eixo da Vigilância em } \\
\text { Saúde Bucal; Continuidade } \\
\text { estabelecida e vinculada à } \\
\text { manutenção da PNSB }\end{array}$ \\
\hline $\begin{array}{l}\text { Capilarização } \\
\text { para estados } \\
\text { e municípios e } \\
\text { incorporação da } \\
\text { metodologia }\end{array}$ & Nenhuma & Nenhuma & $\begin{array}{l}\text { Restrita inicialmente à fase de } \\
\text { execução nos } 250 \text { municípios } \\
\text { sorteados; Indícios claros de } \\
\text { incorporação metodológica } \\
\text { em estados do Nordeste, } \\
\text { Sudeste e Sul que ampliaram } \\
\text { a amostra estadual; } \\
\text { Absorção e incorporação da } \\
\text { metodologia pela Academia }\end{array}$ & $\begin{array}{l}\text { Expansão da amostra em } \\
\text { alguns estados e municípios; } \\
\text { Absorção e incorporação da } \\
\text { metodologia consolidada }\end{array}$ \\
\hline
\end{tabular}

Fonte: Roncalli 8 (atualizado sob permissão); Ministério da Saúde 21.

o SBBrasil 2010, as diferentes probabilidades, em cada estágio de sorteio, foram calculadas de modo a produzir um banco de dados com estas probabilidades e os pesos corrigidos para cada elemento amostral.

Um outro aspecto importante do SBBrasil $2010 \mathrm{diz}$ respeito à sua estratégia operacional. Embora sendo um estudo financiado e coordenado pelo nível federal, a execução se deu, essencialmente, na esfera municipal. Isso exigiu uma ação articulada entre os três diferentes níveis de gestão, com atribuições específicas para cada um deles. Contudo, a coordenação técnica do estudo, no sentido de realizar oficinas de trabalho, treinar as equipes de campo e resolver todos os problemas inerentes à execução da pesquisa, não teria como ocorrer de modo centralizado. Assim, os recém-criados Centros Colaboradores em Vigilância em Saúde Bucal ficaram encarregados da coordenação técnica da pesquisa. Os 177 municípios da amostra foram divididos em oito lotes, sendo que cada um ficou sob a responsabilidade de um determinado Centro Colaborador 10.

Finalmente, nas duas experiências do Projeto SBBrasil implementadas até agora tem havido uma preocupação em compartilhar a construção do projeto com a comunidade científica e dos serviços de saúde, no sentido de construir coletivamente a proposta. A anteprojeto do SBBrasil 2010 foi submetido a uma consulta pública, que ocorreu em junho de 2009. Foram enviadas, ao todo, 131 contribuições, oriundas de 45 municí- pios de 22 estados das cinco regiões brasileiras 10 . Essas contribuições foram analisadas pelo grupo gestor do projeto, sendo que todas foram devidamente respondidas e uma boa parte delas foi incorporada ao projeto final.

\section{O papel dos inquéritos de saúde bucal em um modelo de vigilância}

De acordo com a interessante proposta colocada por Goes 13, a saúde bucal pode ser abordada, do ponto de vista da vigilância em saúde, dentro do escopo das doenças crônicas, dada a natureza da maioria dos agravos em saúde bucal. Para o autor, esse modelo prevê: "(a) mapear o crescimento das DANT (Doenças e Agravos Não-Transmissíveis) $e$ analisar seus determinantes sociais, econômicos, comportamentais e políticos para subsidiar políticas e estratégias de promoção da saúde; (b) reduzir o nível de exposição de indivíduos e populações aos fatores de risco mais comuns para as DANT; (c) fortalecer o sistema de saúde para o controle dos pacientes com DANT; (d) fortalecer redes e parcerias locais, regionais, nacionais $e$ internacionais na área" 13 (p. 264).

A construção de um modelo de vigilância, portanto, passa por uma articulação entre a produção de dados primários e secundários, os quais devem produzir indicadores capazes de gerar informação para a ação. Do ponto de vista dos dados primários, obviamente a maior fonte para produção de indicadores são os inquéritos. 
Analisando a experiência internacional é possível observar que existem diferentes abordagens entre os países, a despeito dos esforços da OMS em tentar padronizar as pesquisas epidemiológicas em saúde bucal desde as primeiras edições de seu principal manual técnico nesta área, o Oral Health Surveys: Basic Methods, já em sua quarta edição, de 1997 9. O Centro Colaborador da OMS da Universidade de Malmö, na Suécia, mantém um sítio na rede mundial de computadores que visa a disseminar informações de saúde bucal dos países membros, o WHO Oral Health Country/Area Profile Programme (CAPP). Essa iniciativa existe desde 1995 e tem procurado mapear, por meio da literatura científica internacional, a situação de cárie dentária (em sua maioria, o CPO aos 12 anos), doença periodontal e fatores de risco para as doenças bucais, bem como informações sobre a rede de serviços 14 .

Para Goes 13, embora diversas experiências em termo de países possam ser salientadas, os modelos adotados pelos Estados Unidos e pelo Reino Unido merecem destaque. No primeiro caso, os inquéritos de saúde bucal nos Estados Unidos estão inseridos no NHANES, um programa que visa a avaliar o estado de saúde e de nutrição de crianças e adultos naquele país desde os anos 1960. A partir de 1999, o NHANES se torna um programa mais regular e os dados de cárie dentária, com base no CPO, foram coletados até 2004, sendo este o último ano com dados disponíveis ${ }^{15}$. No Reino Unido, uma tradição de mais de quatro décadas na produção de informações epidemiológicas de saúde bucal 13 permitiu a criação de "um dos melhores bancos de dados de saúde bucal do mundo", de acordo com própria definição do National Health System (NHS) 16. Desde 1985 dados sistemáticos de cárie dentária em crianças e adultos passaram a ser coletados sob a coordenação da Associação Britânica de Odontologia Comunitária (British Association for the Study of Community Dentistry - BASCD) em todo o território inglês 17. A partir de 2007, uma reformulação legal criou o NHS Dental Epidemiology Programme for England, cabendo, desde então, a responsabilidade pela produção de dados epidemiológicos de saúde bucal ao North West Public Health Observatory (NWPHO) e ao The Dental Observatory (TDO). Os últimos dados disponíveis são de 2009-2010 e permitem avaliar a situação do CPO aos 12 anos nas principais regiões da Inglaterra 16 .

De uma maneira geral, portanto, a maior parte dos países, mesmo os que mantêm bases de dados perenes e têm longa tradição na produção de informações epidemiológicas de saúde bucal, se limitam a trabalhar com indicadores clássicos como o CPO aos 12 anos (expresso em termos de prevalência e severidade). Não são produzidas outras leituras e raramente se incluem outras doenças além da cárie dentária.

Aqui no Brasil, no âmbito da Política Nacional de Saúde, a criação do Comitê Técnico Assessor (CTA) em Vigilância da Saúde Bucal iniciou um importante debate a respeito da construção de indicadores de saúde bucal, com base em dados de inquéritos e do uso dos mesmos em modelos de vigilância nos diferentes níveis de gestão.

A partir da proposta colocada por Goes $13 \mathrm{e}$ outros autores 18 , uma primeira aproximação da matriz de indicadores foi idealizada pelo CTA. Em 2009, Roncalli 19 experimentou o uso dessa matriz com informações do SBBrasil 2003, no sentido de verificar a potencialidade do uso dos dados de inquéritos para a produção de indicadores passíveis de serem utilizados como estratégia de vigilância.

A Tabela 2 ilustra a base teórica de alguns desses indicadores. Além disso, baseando-se no banco de dados do SBBrasil 2003 esses indicadores foram calculados, tendo como base o Brasil e as regiões Nordeste e Sudeste, como um primeiro exercício para verificação de diferenças regionais mais marcantes. Do ponto de vista da estruturação de um modelo de vigilância, estratégias que pautem pela equidade na atenção são fundamentais na organização dos serviços, de modo que o monitoramento de desigualdades no perfil de saúde bucal compõe um dos principais elementos.

De uma maneira geral, observa-se o poder dos indicadores em mostrar as desigualdades regionais de modo bastante claro. Uma situação interessante surge quando analisamos o indicador de crescimento do CPO entre 12 e 15 anos: apesar do CPO aos 12 ser bem mais baixo na Região Sudeste, o aumento em relação aos 15 anos é maior. Há inúmeras possibilidades de interpretação para esses achados, exigindo estudos mais específicos. Entretanto, a redução no ataque de cárie aos 12 anos não se mantém ao longo dos primeiros anos da adolescência. Do ponto de vista dos serviços de saúde, que tradicionalmente trabalham por ciclos de vida, uma maior preocupação tem sido observada nos últimos anos com relação a essa população, em geral mais refratária na busca por estes serviços 20 . Os resultados preliminares do SBBrasil 2010 antes referido apontam na mesma tendência, ou seja, o CPO, mesmo apresentando um valor baixo aos 12 anos, invariavelmente duplica o seu valor na faixa etária de 15 a 19 anos 21 .

Outro ponto relevante que chama atenção é quando analisamos a perda do 1o molar permanente em que a diferença entre o Sudeste e o Nordeste é de mais de 3 vezes. Isso indica, além 
Tabela 2

Indicadores passíveis de serem construídos a partir do CPO-D e resultados para o SBBrasil 2003.

\begin{tabular}{|c|c|c|c|c|c|c|c|c|}
\hline \multirow[t]{2}{*}{ Indicador } & \multirow[t]{2}{*}{ Conceituação } & \multirow[t]{2}{*}{ Interpretação } & \multirow[t]{2}{*}{ Usos } & \multirow{2}{*}{$\begin{array}{l}\text { Método de } \\
\text { cálculo }\end{array}$} & \multirow[t]{2}{*}{ Limitações } & \multicolumn{3}{|c|}{ Resultados para o SBBrasil 2003} \\
\hline & & & & & & Brasil & Nordeste & Sudeste \\
\hline $\begin{array}{l}\text { CPO aos } 12 \\
\text { anos }\end{array}$ & $\begin{array}{l}\text { Número médio } \\
\text { de dentes } \\
\text { atacados pela } \\
\text { cárie (Cariados, } \\
\text { Perdidos e } \\
\text { Obturados) em } \\
\text { crianças de } 12 \\
\text { anos }\end{array}$ & $\begin{array}{c}\text { Retrata o } \\
\text { ataque de } \\
\text { cárie de uma } \\
\text { maneira geral, } \\
\text { quando a } \\
\text { criança acaba } \\
\text { de compor } \\
\text { sua dentição } \\
\text { permanente; } \\
\text { Segundo a } \\
\text { OMS, valores } \\
\text { até } 1,1 \text { são } \\
\text { considerados } \\
\text { muito baixos, } \\
\text { de 1,2 a 2,6 } \\
\text { baixos, de } 2,7 \\
\text { a 4,4 médios, } \\
\text { de } 4,5 \text { a 6,5 } \\
\text { altos e acima } \\
\text { de } 6,5 \text { muito } \\
\text { altos }\end{array}$ & $\begin{array}{l}\text { Monitoramento } \\
\text { global de cárie } \\
\text { dentária em } \\
\text { nível municipal, } \\
\text { regional e } \\
\text { nacional }\end{array}$ & $\begin{array}{c}\text { Somatório dos } \\
\text { componentes } \\
\text { Cariado, } \\
\text { Restaurado } \\
\text { e Cariado, } \\
\text { Restaurado e } \\
\text { Extraído por } \\
\text { cárie/Total } \\
\text { de indivíduos } \\
\text { examinados }\end{array}$ & $\begin{array}{c}\text { Perde poder } \\
\text { discriminatório } \\
\text { em situações de } \\
\text { alta prevalência } \\
\text { e severidade; } \\
\text { Pouco sensível } \\
\text { a mudanças em } \\
\text { curto espaço de } \\
\text { tempo }\end{array}$ & 2,78 & 3,19 & 2,30 \\
\hline $\begin{array}{l}\text { Proporção de } \\
\text { livres de cárie } \\
\text { (5 e } 12 \text { anos) }\end{array}$ & $\begin{array}{l}\text { Percentual de } \\
\text { indivíduos com } \\
\text { CPO ou } \\
\text { ceo }=0\end{array}$ & $\begin{array}{c}\text { Estima a } \\
\text { prevalência } \\
\text { de doença } \\
\text { em dentes } \\
\text { decíduos } \\
\text { (5 anos) e } \\
\text { permanen-tes } \\
\text { (12 anos) }\end{array}$ & $\begin{array}{l}\text { Monitoramento } \\
\text { global de cárie } \\
\text { dentária em } \\
\text { nível municipal, } \\
\text { regional e } \\
\text { nacional }\end{array}$ & $\begin{array}{l}\text { Número de } \\
\text { indivíduos } \\
\text { com CPO ou } \\
\text { ceo = 0/Total } \\
\text { de indivíduos } \\
\text { examinados } \\
\text { x } 100\end{array}$ & $\begin{array}{c}\text { Limitações } \\
\text { semelhantes aos } \\
\text { CPO aos } 12 \text { anos }\end{array}$ & $\begin{array}{c}5 \text { anos: } \\
40,62 \% ; 12 \\
\text { anos: } 31,08 \%\end{array}$ & $\begin{array}{c}5 \text { anos: } \\
\text { 34,92\%; } 12 \\
\text { anos: } 27,52 \%\end{array}$ & $\begin{array}{l}5 \text { anos: } \\
44,92 \% ; \\
12 \text { anos: } \\
37,58 \%\end{array}$ \\
\hline $\begin{array}{l}\text { Crescimento } \\
\text { CPO entre } \\
12-15 \text { anos }\end{array}$ & $\begin{array}{c}\text { Diferença } \\
\text { proporcional } \\
\text { entre o CPO-D } \\
\text { aos } 12 \text { anos e } \\
\text { aos } 15 \text { anos }\end{array}$ & $\begin{array}{l}\text { Estima a força } \\
\text { com que a } \\
\text { cárie dentária } \\
\text { aumenta em } \\
\text { relação à } \\
\text { idade; Dos } 12 \\
\text { aos } 15 \text { anos } \\
\text { é um período } \\
\text { crítico do } \\
\text { ponto de vista } \\
\text { da assistência } \\
\text { odontológica }\end{array}$ & $\begin{array}{l}\text { Em situações } \\
\text { em que é } \\
\text { difícil realizar } \\
\text { estudos de } \\
\text { incidência, este } \\
\text { indicador pode } \\
\text { dar uma ideia } \\
\text { aproximada da } \\
\text { evolução da } \\
\text { doença; Pode } \\
\text { também ser } \\
\text { calculado para } \\
\text { cada um dos } \\
\text { componentes }\end{array}$ & $\begin{array}{l}\text { (CPO aos } 15 \\
\text { anos }- \text { CPO } \\
\text { aos } 12 \text { anos)/ } \\
\text { CPO aos } 12 \\
\text { anos } \times 100\end{array}$ & $\begin{array}{l}\text { Dificuldade de } \\
\text { realizar o exame } \\
\text { em adolescentes } \\
\text { de } 15 \text { anos em } \\
\text { situações de alta } \\
\text { evasão escolar; } \\
\text { É uma estimativa } \\
\text { de incidência com } \\
\text { dados prevalentes, } \\
\text { devendo ser } \\
\text { analisado com } \\
\text { cautela }\end{array}$ & $79,93 \%$ & $57,05 \%$ & $107,39 \%$ \\
\hline
\end{tabular}

(continua) 
Tabela 2 (continuação)

\begin{tabular}{|c|c|c|c|c|c|c|c|c|}
\hline \multirow[t]{2}{*}{ Indicador } & \multirow[t]{2}{*}{ Conceituação } & \multirow[t]{2}{*}{ Interpretação } & \multirow[t]{2}{*}{ Usos } & \multirow{2}{*}{$\begin{array}{l}\text { Método de } \\
\text { cálculo }\end{array}$} & \multirow[t]{2}{*}{ Limitações } & \multicolumn{3}{|c|}{ Resultados para o SBBrasil 2003} \\
\hline & & & & & & Brasil & Nordeste & Sudeste \\
\hline $\begin{array}{l}\text { Cárie não } \\
\text { tratada }(5,12 \\
\text { e 15-19 anos) }\end{array}$ & $\begin{array}{l}\text { Proporção dos } \\
\text { componentes } \\
\text { Cariado e } \\
\text { Restaurado / } \\
\text { Cariado em } \\
\text { relação ao } \\
\text { CPO }\end{array}$ & $\begin{array}{c}\text { Retrata } \\
\text { indiretamente } \\
\text { o acesso } \\
\text { aos serviços } \\
\text { de caráter } \\
\text { curativo; } \\
\text { Interpreta-se } \\
\text { como o inverso } \\
\text { do Índice de } \\
\text { Cuidados e, } \\
\text { quanto maior, } \\
\text { pior a situação }\end{array}$ & $\begin{array}{c}\text { Pode ser } \\
\text { utilizado em } \\
\text { todos os níveis, } \\
\text { desde o local ao } \\
\text { nacional para a } \\
\text { estimativa das } \\
\text { necessidades } \\
\text { de tratamento } \\
\text { e, conse- } \\
\text { quentemente, } \\
\text { para o cálculo } \\
\text { dos recursos } \\
\text { necessários }\end{array}$ & $\begin{array}{c}\text { Total de } \\
\text { Cariados } \\
+ \text { Total de } \\
\text { Restaurados } \\
\text { mas cariados/ } \\
\text { CPO-D Total } \\
\times 100\end{array}$ & $\begin{array}{c}\text { Mesmas limitações } \\
\text { do CPO de uma } \\
\text { maneira geral; } \\
\text { Pode subestimar } \\
\text { as necessidades } \\
\text { por conta de } \\
\text { imprecisão no } \\
\text { diagnóstico; } \\
\text { Estima apenas } \\
\text { o tratamento } \\
\text { curativo para a } \\
\text { cárie }\end{array}$ & $\begin{array}{c}5 \text { anos: } \\
\text { 82,14\%; } 12 \\
\text { anos: } 58,27 \% ; \\
\text { 15-19 anos: } \\
42,14 \%\end{array}$ & $\begin{array}{c}5 \text { anos: } \\
90,65 \% ; 12 \\
\text { anos: } 71,47 \% ; \\
15-19 \text { anos: } \\
52,37 \%\end{array}$ & $\begin{array}{c}5 \text { anos: } \\
75,60 \% ; \\
12 \text { anos: } \\
42,17 \% ; \\
15-19 \text { anos: } \\
28,96 \%\end{array}$ \\
\hline $\begin{array}{l}\text { Índice de } \\
\text { Cuidados } \\
\text { Odontológi- } \\
\cos (5,12 \text { e } \\
15-19 \text { anos })\end{array}$ & $\begin{array}{l}\text { Proporção do } \\
\text { componente } \\
\text { Restaurado } \\
\text { em relação ao } \\
\text { CPO-D total }\end{array}$ & $\begin{array}{l}\text { Expressa a } \\
\text { cobertura } \\
\text { para serviços } \\
\text { restauradores. } \\
\text { Quanto mais } \\
\text { próximo de } \\
100, \text { maior } \\
\text { o acesso a } \\
\text { procedimentos } \\
\text { restauradores }\end{array}$ & $\begin{array}{c}\text { Pode ser } \\
\text { utilizado em } \\
\text { todos os níveis, } \\
\text { desde o local ao } \\
\text { nacional }\end{array}$ & $\begin{array}{c}\text { Total de } \\
\text { Restaurados/ } \\
\text { CPO-D } \\
\text { Total x } 100\end{array}$ & $\begin{array}{c}\text { Mesmas limitações } \\
\text { do CPO de } \\
\text { uma maneira } \\
\text { geral; Deve ser } \\
\text { interpretado } \\
\text { juntamente com } \\
\text { o CPO total, pois } \\
\text { pode indicar } \\
\text { sobretratamento }\end{array}$ & $\begin{array}{c}5 \text { anos: } \\
\text { 12,86\%; } 12 \\
\text { anos: } 32,73 \% ; \\
\text { 15-19 anos: } \\
40,36 \%\end{array}$ & $\begin{array}{c}5 \text { anos: } 4,67 \% ; \\
12 \text { anos: } \\
\text { 18,81\%; } 15-19 \\
\text { anos: } 26,66 \%\end{array}$ & $\begin{array}{c}5 \text { anos: } \\
\text { 20,00\%; } \\
12 \text { anos: } \\
52,17 \% ; \\
15-19 \text { anos: } \\
59,26 \%\end{array}$ \\
\hline $\begin{array}{l}\text { Mutilação } \\
\text { dentária (15- } \\
\text { 19, 35-44 e } \\
65-74 \text { anos) }\end{array}$ & $\begin{array}{l}\text { Proporção do } \\
\text { componente } \\
\text { Perdido por } \\
\text { cárie em } \\
\text { relação ao } \\
\text { CPO }\end{array}$ & $\begin{array}{c}\text { Expressa } \\
\text { o caráter } \\
\text { mutilador do } \\
\text { serviço }\end{array}$ & $\begin{array}{l}\text { Mais indicado } \\
\text { para uso em } \\
\text { nível municipal, } \\
\text { estadual e } \\
\text { nacional }\end{array}$ & $\begin{array}{l}\text { Total de } \\
\text { Extraídos por } \\
\text { cárie/CPO-D } \\
\text { Total x } 100\end{array}$ & $\begin{array}{c}\text { Mesmas limitações } \\
\text { do CPO de uma } \\
\text { maneira geral; } \\
\text { Sofre mudanças } \\
\text { em espaços de } \\
\text { tempo muito } \\
\text { grandes }\end{array}$ & $\begin{array}{c}15-19 \text { anos: } \\
\text { 14,42\%; 35-44 } \\
\text { anos: } 65,72 \% ; \\
\text { 65-74 anos: } \\
92,95 \%\end{array}$ & $\begin{array}{c}\text { 15-19 anos: } \\
\text { 18,14\%; 35-44 } \\
\text { anos: 71,87\%; } \\
\text { 65-74 anos: } \\
\text { 92,41\% }\end{array}$ & $\begin{array}{c}\text { 15-19 anos: } \\
\text { 8,75\%; 35- } \\
44 \text { anos: } \\
\text { 57,34\%; } \\
\text { 65-74 anos: } \\
94,55 \%\end{array}$ \\
\hline $\begin{array}{l}\text { Perda do } \\
\text { 1ㅇ molar } \\
\text { permanente } \\
\text { (12 anos) }\end{array}$ & $\begin{array}{c}\text { Número médio } \\
\text { dos elementos } \\
16,26,36 \text { e } \\
46 \text { codificados } \\
\text { como perdidos } \\
\text { por cárie }\end{array}$ & $\begin{array}{c}\text { Complementa } \\
\text { a leitura das } \\
\text { características } \\
\text { mutiladoras } \\
\text { do modelo, } \\
\text { acrescentando } \\
\text { uma medida } \\
\text { mais recente } \\
\text { que o } \\
\text { edentulismo } \\
\text { em adultos; } \\
\text { Expressa a } \\
\text { incapacidade } \\
\text { do serviço } \\
\text { em preservar } \\
\text { as estruturas } \\
\text { dentárias e } \\
\text { em prevenir a } \\
\text { doença }\end{array}$ & $\begin{array}{c}\text { Pode ser } \\
\text { utilizado em } \\
\text { todos os níveis, } \\
\text { desde o local ao } \\
\text { nacional }\end{array}$ & $\begin{array}{c}\text { Número de } \\
\text { elementos } 16, \\
\text { 26, } 36 \text { ou } 46 \\
\text { codificados } \\
\text { como Perdido } \\
\text { por cárie/Total } \\
\text { de indivíduos } \\
\text { examinados }\end{array}$ & $\begin{array}{c}\text { Mesmas limitações } \\
\text { do CPO de uma } \\
\text { maneira geral }\end{array}$ & 0,14 & 0,19 & 0,06 \\
\hline
\end{tabular}

(continua) 
Tabela 2 (continuação)

\begin{tabular}{|c|c|c|c|c|c|c|c|c|}
\hline \multirow[t]{2}{*}{ Indicador } & \multirow[t]{2}{*}{ Conceituação } & \multirow[t]{2}{*}{ Interpretação } & \multirow[t]{2}{*}{ Usos } & \multirow{2}{*}{$\begin{array}{l}\text { Método de } \\
\text { cálculo }\end{array}$} & \multirow[t]{2}{*}{ Limitações } & \multicolumn{3}{|c|}{ Resultados para o SBBrasil 2003} \\
\hline & & & & & & Brasil & Nordeste & Sudeste \\
\hline $\begin{array}{l}\text { Funcionali- } \\
\text { dade dentária }\end{array}$ & $\begin{array}{c}\text { Proporção de } \\
\text { indivíduos com } \\
\text { Perdido = } 0 \\
\text { aos } 18 \text { anos; } \\
\text { Proporção de } \\
\text { indivíduos de } \\
35 \text { a } 44 \text { anos } \\
\text { e de } 65 \text { a } 74 \\
\text { anos com } \\
\text { pelo menos } \\
20 \text { dentes } \\
\text { funcionais }\end{array}$ & $\begin{array}{c}\text { Expressa a } \\
\text { capacidade } \\
\text { do serviço } \\
\text { em manter } \\
\text { os dentes na } \\
\text { boca, evitando } \\
\text { extrações } \\
\text { desnecessárias }\end{array}$ & $\begin{array}{c}\text { Mais indicado } \\
\text { para uso em } \\
\text { nível municipal, } \\
\text { estadual e } \\
\text { nacional }\end{array}$ & $\begin{array}{c}\text { Número de } \\
\text { indivíduos com } \\
\text { Perdido }= \\
\text { 0/Total de } \\
\text { indivíduos } \\
\text { examinados x } \\
\text { 100; Número } \\
\text { de indivíduos } \\
\text { com Perdido } \\
\leq 12 / \text { Total de } \\
\text { indivíduos } \\
\text { examinados } \\
\times 100\end{array}$ & $\begin{array}{c}\text { Mesmas limitações } \\
\text { do CPO de uma } \\
\text { maneira geral }\end{array}$ & $\begin{array}{c}18 \text { anos: } \\
\text { 55,09\%; 35-44 } \\
\text { anos: 53,96\%; } \\
\text { 65-74 anos: } \\
\text { 10,23\% }\end{array}$ & $\begin{array}{c}18 \text { anos: } \\
45,07 \% ; 35-44 \\
\text { anos: } 49,97 \% ; \\
65-74 \text { anos: } \\
11,07 \%\end{array}$ & $\begin{array}{c}18 \text { anos: } \\
\text { 66,53\%; } \\
\text { 35-44 anos: } \\
\text { 62,35\%; } \\
65-74 \text { anos: } \\
9,32 \%\end{array}$ \\
\hline
\end{tabular}

OMS: Organização Mundial da Saúde.

Fonte: adaptado de Roncalli 19 (reproduzido sob permissão).

de uma maior prevalência e severidade, uma baixa qualidade na assistência, essencialmente mutiladora.

O Índice de Cuidados Odontológicos, proposto inicialmente por Walsh (1970) e citado por Antunes et al. 18, permite analisar o acesso aos serviços restauradores e expressa de modo claro a desigualdade neste acesso: no caso dos dentes decíduos, é uma diferença assustadora de mais de 5 vezes entre as regiões Nordeste e Sudeste. O mesmo se mostra quando se analisa o indicador inverso a este, de cárie não tratada, bem como o indicador de mutilação dentária.

Com relação à funcionalidade dentária, tratase de uma proposta estabelecida desde a publicação das metas em saúde bucal para o ano 2000 por parte da World Dental Federation (FDI), em 1981 22. Como se pode notar, a distância dessas metas é bem diferente entre as regiões. A manutenção de um maior número possível de dentes naturais na boca expressa a qualidade dos serviços do ponto de vista preventivo e terapêutico, e desonera de modo bastante significativo os serviços de atenção secundária e reabilitadora.

Foram incluídos nesta primeira aproximação apenas os indicadores obtidos baseando-se no CPO, contudo, outros indicadores podem ser construídos tendo como base outros agravos. Conforme salienta Goes 13, além dos dados pri- mários e secundários relativos aos agravos em saúde bucal é importante que sejam incorporados, a estes indicadores normativos tradicionais, outros que deem conta do impacto produzido por estas condições. No Projeto SBBrasil 2010 foram incluídas variáveis relativas a esses impactos e, desse modo, espera-se que na sequência das análises realizadas com o banco de dados da pesquisa estes indicadores possam ser produzidos e disseminados.

\section{Considerações finais}

Os inquéritos de saúde bucal no Brasil estão atingindo sua maturidade e têm grandes possibilidades de se estabelecer como importante ferramenta tanto do ponto de vista acadêmico quanto do uso em serviços de saúde. Para isso, é fundamental que o Projeto SBBrasil se consolide enquanto estratégia de produção de dados primários inserida no eixo da Vigilância em Saúde da Política Nacional de Saúde Bucal. Neste artigo, tentamos demonstrar sua potencialidade em verificar tendências no perfil de saúde bucal, bem como em produzir indicadores válidos para uso em serviços, de modo que se torna igualmente necessário que estas práticas se disseminem em todos os níveis de gestão. 


\section{Resumo}

Inquéritos nacionais são importantes ferramentas no campo da vigilância em saúde e elementos fundamentais no monitoramento das condições de saúde e do desempenho do sistema. Na saúde bucal, tais inquéritos surgem a partir do primeiro levantamento em saúde bucal de 1986 e, posteriormente, o de 1996 e o Projeto SBBrasil 2003. A edição 2010 do SBBrasil se coloca como a principal estratégia de vigilância em saúde bucal no que diz respeito à produção de dados primários. No sentido de contribuir com essa discussão, este artigo se propôs a: (a) apresentar e discutir a experiência brasileira em inquéritos nacionais de saúde bucal; (b) discutir a utilização dos dados em modelos de vigilância em saúde. Pode-se concluir que os inquéritos de saúde bucal no Brasil têm grandes possibilidades de se estabelecer como ferramenta para os serviços e para a academia. Ficou evidente sua potencialidade em verificar tendências no perfil de saúde bucal, bem como em produzir indicadores válidos para uso em serviços.

Inquéritos de Saúde Bucal; Saúde Bucal; Vigilância Epidemiológica

\section{Colaboradores}

A. G. Roncalli concebeu a estrutura do artigo, analisou os bancos de dados e colaborou na redação do texto. M. I. S. Cortes colaborou na análise dos dados e na redação do texto. K. G. Peres colaborou na análise dos dados e na redação do texto.

\section{Referências}

1. Viacava F. Informações em saúde: a importância dos inquéritos populacionais. Ciênc Saúde Coletiva 2002; 7:607-21.

2. Barros MBA. Inquéritos domiciliares de saúde: potencialidades e desafios. Rev Bras Epidemiol 2008; 11 Suppl 1:6-19.

3. Cesar CLG, Tanaka OY. Inquérito domiciliar como instrumento de avaliação de serviços de saúde: um estudo de caso na região sudoeste da área metropolitana de São Paulo, 1989-1990. Cad Saúde Pública 1996; 12 Suppl 2:59-70.

4. Waldman EA, Novaes HMD, Albuquerque MFM, Latorre MRDO, Ribeiro MCSA, Vasconcellos M, et al. Inquéritos populacionais: aspectos metodológicos, operacionais e éticos. Rev Bras Epidemiol 2008; 11 Suppl 1:168-79.

5. Narvai PC. Saúde bucal coletiva: caminhos da odontologia sanitária à bucalidade. Rev Saúde Pública 2006; 40(N Esp):141-7.

6. Divisão Nacional de Saúde Bucal, Ministério da Saúde. Levantamento epidemiológico em saúde bucal: Brasil, zona urbana. Brasília: Ministério da Saúde; 1986.
7. Roncalli AG. Levantamentos epidemiológicos em saúde bucal no Brasil. In: Antunes JLF, Peres MA, organizadores. Epidemiologia da saúde bucal. Rio de Janeiro: Editora Guanabara Koogan; 2006. p. 32-48.

8. Roncalli AG. Epidemiologia e saúde bucal coletiva: um caminhar compartilhado. Ciênc Saúde Coletiva 2006; 11:105-14.

9. World Health Organization. Oral health surveys: basic methods. $4^{\text {th }}$ Ed. Geneva: World Health Organization; 1997.

10. Coordenação Nacional de Saúde Bucal, Departamento de Atenção Básica, Ministério da Saúde. Pesquisa Nacional de Saúde Bucal, SBBrasil 2010: projeto técnico. http://www.sbbrasil2010.org (acessado em 20/Dez/2010).

11. Queiroz RCS, Portela MC, Vasconcellos MTL. Pesquisa sobre as Condições de Saúde Bucal da População Brasileira (SB Brasil 2003): seus dados não produzem estimativas populacionais, mas há possibilidade de correção. Cad Saúde Pública 2009; 25:47-58. 
12. Narvai PC, Antunes JLF, Moysés SJ, Frazão P, Peres MA, Peres KG, et al. Validade científica de conhecimento epidemiológico gerado com base no estudo Saúde Bucal Brasil 2003. Cad Saúde Pública 2010; 26:647-70.

13. Goes PSA. Vigilância da saúde bucal para o nível local: uma abordagem integrada para as equipes de saúde bucal da Estratégia Saúde da Família. In: Moysés ST, Kriger L, Moysés SJ, organizadores. Saúde bucal das famílias: trabalhando com evidências. São Paulo: Editora Artes Médicas; 2008. p. 258-67.

14. World Health Organization Collaborating Centre. WHO oral health country/area profile programme. http://www.whocollab.od.mah.se (acessado em 05/Jan/2011).

15. U.S. Department of Health and Human Services/ Center for Disease Control and Prevention/National Center for Health Statistics. National Health and Nutrition Examination Survey, 2007-2008: overview. Hyattsville: National Center for Health Statistics; 2009.

16. Rooney E, Perkins C. NHS Dental Epidemiology Programme for England: report June 2010. Liverpool: National Health System; 2010.

17. Pine C, Pitts NB, Nugent ZJ. British Association for the study of Community Dentistry (BASCD) guidance on sampling for surveys of child dental health. A BASCD coordinated dental epidemiology programme quality standard. Community Dental Health 1997; 14 Suppl 1:1-17.
18. Antunes JLF, Peres MAA, Frazão P. Cárie dentária. In: Antunes JLF, Peres MAA, organizadores. Epidemiologia da saúde bucal. Rio de Janeiro: Editora Guanabara Koogan; 2006. p. 49-67.

19. Roncalli AG. Indicadores de saúde e de saúde bucal: desafios para seu uso em modelos assistenciais. In: Pereira AC, organizador. Tratado de saúde coletiva em odontologia. São Paulo: Napoleão; 2009. p. 414-30.

20. Coordenação Nacional de Saúde Bucal, Departamento de Atenção Básica, Secretaria de Atenção à Saúde, Ministério da Saúde. Diretrizes da Política Nacional de Saúde Bucal. Brasília: 2004. Brasília: Ministério da Saúde; 2004.

21. Coordenação Nacional de Saúde Bucal, Departamento de Atenção Básica, Secretaria de Atenção à Saúde, Ministério da Saúde. Pesquisa Nacional de Saúde Bucal, SBBrasil 2010: nota para a imprensa. Brasília: Ministério da Saúde; 2010.

22. Federation Dentaire Internacionale. Global goals for oral health in the year 2000. Int Dent J 1982; 32:74-7.

Recebido em 14/Jan/2011

Versão final reapresentada em 14/Mar/2011

Aprovado em 29/Ago/2011 